\title{
On the study of tailorable interface structure in a diamond/Al12Si composite processed by selective laser melting
}

Y. Ma ${ }^{\mathrm{a}, \mathrm{b}}$, G. Ji ${ }^{\mathrm{a},{ }^{*}}$, X.P. Li ${ }^{\mathrm{c}, \mathrm{d},{ }^{*}, \text { C.Y. Chen }}{ }^{\mathrm{e}}$, Z.Q. $\operatorname{Tan}^{\mathrm{f}}$, A. Addad ${ }^{\mathrm{a}}$, Z.Q. Li ${ }^{\mathrm{f}}$, T.B. Sercombe ${ }^{\mathrm{g}}$, J.P. Kruth ${ }^{\mathrm{d}}$

${ }^{a}$ Unité Matériaux et Transformations, CNRS UMR 8207, Université de Lille, Villeneuve d'Ascq 59655, France

${ }^{b}$ Institut de chimie moléculaire et des matériaux d'Orsay, CNRS UMR 8182, Université Paris-Sud, Orsay 91405 , France

${ }^{c}$ School of Mechanical and Manufacturing Engineering, The University of New South Wales, NSW 2052, Australia

${ }^{d}$ KU Leuven (University of Leuven), Department of Mechanical Engineering, Leuven 3001, Belgium

${ }^{e}$ State Key Laboratory of Advanced Special Steels, School of Materials Science and Engineering, Shanghai University, Shanghai 200444, PR China

${ }^{f}$ State Key Laboratory of Metal Matrix Composites, School of Materials Science and Engineering, Shanghai Jiao Tong University, Shanghai 200240, PR China

${ }^{g}$ School of Mechanical and Chemical Engineering, The University of Western Australia, 35 Stirling Highway, Perth, WA 6009, Australia

*Corresponding authors: gang.ji@univ-lille1.fr(Dr. Gang JI); xiaopeng.li@unsw.edu.au (Dr. Xiaopeng LI)

\begin{abstract}
Aluminum-diamond composites were produced using selective laser melting (SLM) from mechanically mixed diamond and Al12Si powders for use in thermal management applications. The feasibility of SLM for both interface tailoring and simultaneously densification, which are the key for determining the overall thermal conductivity (TC) of the
\end{abstract}


composites, has been investigated. The results indicate that the interface structure of the as-built composites can be controlled, despite the complex physical and chemical nature of SLM. A 'clean' diffusion-bonded interface revealed at the micron scale, which is desirable for enhancing TC, was obtained at a laser energy density of $95.2 \mathrm{~J} / \mathrm{mm}^{3}$. This demonstrates a possible new potential of SLM in creating metal matrix composites for functional applications. However, despite manipulation of the processing parameters, it was not possible to achieve a relative density above $90 \%$. Thus, how to realize near full density, while maintaining such a 'clean' interface during SLM remains a key technical problem for the future. The complex metallurgical mechanisms responsible for interface evolution and microstructure formation are discussed in detail with the aid of finite element analysis, and further densification strategies are proposed.

Keywords: Metal matrix composites; Thermal properties; Selective laser melting; Additive manufacturing; Interface characterization 


\section{Introduction}

Selective laser melting (SLM), originally developed in Germany in 1995, is one of the most promising additive manufacturing (AM) technologies. With respect to conventional manufacturing techniques (e.g. powder metallurgy and casting), it enables rapid production of a 3D metallic component by selectively melting a powder bed using a high-power laser. The layer-by-layer characteristic of SLM starts by slicing the 3D computer-aided design file of the part into 2D layers and, then loads this file directly into the build preparation software. The absence of any other processing equipment can significantly reduce the production costs. The other key benefit of SLM is that it facilitates design and fabrication of geometrically extremely complex parts [1-4].

In recent dedicated review papers, SLM of metals, alloys and metal matrix composites (MMCs) have been discussed with the view of extending AM applicable powders, establishing an AM process database and understanding the complex metallurgical mechanisms [5-7]. Successful SLM of Al alloys with enhanced mechanical properties has been mainly reported on casting alloys such as Al12Si [8], AlSi10Mg [9] and AlSi7Mg [10], and only very recently being extended to the higher strength wrought alloys, such as 2218 (Al-Cu-Mg-Si) [11], 7075 (Al-Zn-Mg-Cu) and 6061 (Al-Mg-Si-Cu) [12]. Work on SLM processed ex-situ aluminium matrix composites has focused on the use of micron-sized reinforcement particles in an $\mathrm{Al}$ alloy matrix, including SiC/A14.5Cu3Mg [13, 14], TiC/AlSi10Mg [15], SiC/Al12Si [6, 16], Al-Fe$\mathrm{Cr}$ quasicrystal/ $\alpha-\mathrm{Al}$ [17] or nanosized additions, such as CNT/AlSi10Mg [18], $\mathrm{Al}_{2} \mathrm{O}_{3} / \mathrm{Al}$ [19] and AlN/AlSi10Mg [20]. Also, regarding the SLM-processed MMCs, attention has only been paid to mechanical rather than functional properties, which to some extent limits the applications of SLM.

In the microelectronics industry, the driving force for the development of high thermal conductivity materials for thermal management applications stems from the ever higher 
temperatures caused by a continuous increase in the power density of chips [21]. The first report of a diamond/Al MMC, as one of the most promising material candidates for heat sinks, was in 1993 when Johnson et al. [22] produced such a product by pressureless infiltration. However, the best thermal conductivity (TC) measured was $259 \mathrm{~W} / \mathrm{m} \mathrm{K}$, which was only slightly higher than that of the pure Al matrix $(205 \mathrm{~W} / \mathrm{m} \mathrm{K})$. Since then, significant progress has been made on TC enhancement and developing an understanding of the enhancement mechanisms. Conventional powder metallurgy and casting have been the two most popular processing routes explored so far. For example, it has been reported that diamond $(50$ vol.\%)/Al composite produced by vacuum hot pressing (VHP) has reached a TC of around $500 \mathrm{~W} / \mathrm{m} \mathrm{K}$ after optimization of the processing conditions [23]. This has been increase to $600 \mathrm{~W} / \mathrm{m} \mathrm{K}$ by using $\mathrm{W}$-coated diamond particles [24]. Even higher TCs of up to $\sim 740 \mathrm{~W} / \mathrm{m} \mathrm{K}$ have been reported from pressure infiltrated diamond (around $60 \mathrm{vol} . \%$ )/Al composites, but the conductivity is dependent on both the diamond quality and processing conditions $[25,26]$. It is generally considered that full densification and avoiding excess formation of $\mathrm{Al}_{4} \mathrm{C}_{3}$ are the two necessary criteria to acquire enhanced TC [25-28]. Therefore, tailoring the diamond/Al interface (bonding, chemistry, etc.) by controlling the nucleation and growth of the interfacial reaction product $\mathrm{Al}_{4} \mathrm{C}_{3}$, is an essential step in enhancing overall TC of composite [25-28]. In addition, it has been demonstrated by ion-beam assisted scanning electron microscopy (SEM) and transmission electron microscopy (TEM) that a 'clean' diffusion-bonded diamond/Al interface (referred to 'clean' interface hereafter) is the key requirement for TC enhancement [29]. It is characterised by a tightly-bonded (i.e. no interfacial porosity) and clean interface without containing interfacial $\mathrm{Al}_{4} \mathrm{C}_{3}$ at the micron scale, while the limited formation of $\mathrm{Al}_{4} \mathrm{C}_{3}$ observed at the nanoscale still confirms its chemical bonding nature.

The nucleation of $\mathrm{Al}_{4} \mathrm{C}_{3}$ is intrinsically selective due to different carbon atom arrangements on (100) and (111) facets of diamond particles [30] and, its heterogeneous morphology has been 
revealed at the different length scales from nano- $[27,28]$ up to micron scales $[25,26]$. Both VHP and gas-pressure infiltration techniques generally facilitate an acceptable level interfacial control of $\mathrm{Al}_{4} \mathrm{C}_{3}$ such that TC enhancement is possible $[25,26,28]$.

SLM processing of the diamond/Al composite with a high TC is of significant interest, since net-shape forming of air-cooled geometrically-complex heat sinks (e.g. pin, fins and V-shaped [31]) is much more easily achieved than with other conventional manufacturing techniques. This is particularly true given the poor machinability of the hard diamond particles. Further, it has been demonstrated in SLMed SiC (10 vol.\%)/A112Si composites [16], the input laser energy plays a key role in determining the quantity of interfacial $\mathrm{Al}_{4} \mathrm{C}_{3}$ that forms (i.e. the extent of the interfacial reaction). However, compared with the above-mentioned conventional techniques, it seems that the much more complex physical and chemical nature of SLM renders the delicate interface tailoring less feasible to not to form the 'clean' interface at the micron scale.

SLM of materials containing diamond single crystal particles is potentially technically challenging since diamond has a very high TC (in the range 1500-2500 W/m K) and a very high melting temperature $\left(\sim 3500{ }^{\circ} \mathrm{C}\right)$. In this work, diamond (10 vol.\%)/Al12Si composites have been produced with the aim at testing the new feasibility of SLM for both interface tailoring and simultaneously densification, being essential for enhancing the overall TC of the composites. The evolution of the interfacial structure, being closely associated with laser energy density, has been revealed by microstructural characterization at the various scales. Following this, the relevant complex metallurgical mechanisms have been discussed with the aid of finite element simulation.

\section{Experimental procedures}

\subsection{Starting materials and SLM processing}


A synthetic diamond powder (Type HWD40, Henan Huanghe Whirlwind International Co. Ltd., China, $30 \mu \mathrm{m}$ in average particle size) and an Al12Si (in wt.\%) powder (TLS Technik, Germany, particle size range $25-45 \mu \mathrm{m}$ ) were used as reinforcement and matrix materials, respectively. Their faceted and quasi-spherical morphologies are displayed in Figs. 1a and 1b, respectively. Diamond powder was first ultrasonically washed using distilled water and dried. A homogenous diamond (10 vol.\%)/Al12Si composite powder mixture was obtained by mechanical mixing for 30 min using a mixer (Turbula, TF2) with the rotation speed set to around $100 \mathrm{rpm}$.

An in-house built SLM machine at KU Leuven in Belgium was used to produce the parts. It was equipped with a fibre laser having a laser wavelength of $1.06 \mu \mathrm{m}$ and a maximum power of $300 \mathrm{~W}$ at the powder bed. An inert, high purity argon gas atmosphere was used during the whole process to minimise oxidation. The laser power $(p)$, powder layer thickness $(t)$ and scan spacing $(s)$ was set to $300 \mathrm{~W}, 30 \mu \mathrm{m}$, and $105 \mu \mathrm{m}$, respectively. No powder pre-heating was used. Scan speeds $(v)$ in the range $600-1600 \mathrm{~mm} / \mathrm{s}$ were used to investigate the densification of pure Al12Si powder and diamond/Al12Si powder mixtures. Volumetric laser energy density (E) was given by $E=\frac{P}{v s t}[32]$. Fig. 1c shows four examples of the SLM-processed disk samples, which have a diameter of $12 \mathrm{~mm}$.

\subsection{Microstructure characterization and measurement of physical properties}

The cross-sections (parallel to building direction) of as-built pure Al12Si and diamond/Al12Si composite samples were cut and mechanically polished using standard metallographic techniques. They were then finished by surface ion-milling, using a Fischione instruments model 1060 miller, and were characterized by X-ray diffraction (XRD) and SEM. Surface ion-milling time was limited to that acquired to produce a flat interfacial area in order to prevent possible harmful ion implantation. XRD measurements were done using a Rigaku SMARTLAB multipurpose diffractometer ( $9 \mathrm{~kW}$ rotating anode) in Bragg-Brentano reflection 
beam mode (with a PSD 1D detector DTEX) delivering $\mathrm{Cu}-\mathrm{K}_{\alpha}$ radiation $(\lambda=1.5418 \AA$ ). Scans were performed between $2 \theta$ of 30 and $80^{\circ}$ at a scan speed of $4^{\circ} / \mathrm{min}$. A JEOL JSM-7800F scanning electron microscope, equipped with a field emission gun (FEG) and an Oxford energy dispersive X-ray (EDX) spectrometry system, was used for SEM.

A TEM sample was prepared from $3 \mathrm{~mm}$ diameter disk of pure A112Si by mechanical thinning followed by ion milling, using a Gatan Model 691 precision ion polishing system. A STRATA DB 235 dual beam focus ion beam (FIB) instrument was employed to prepare sitespecific TEM samples that contained with the diamond/Al interface or the matrix area away from such an interface. A FEI Tecnai G2 twin microscope, operated at $200 \mathrm{kV}$ and equipped with an Oxford EDX spectrometry system, was used for TEM characterization. Scanning TEMEDX map was acquired on a FEI Titan Themis 300 microscope, operated at $200 \mathrm{kV}$ and equipped with a probe aberration corrector and a high-efficient (4 quadrant) EDX detector.

Thermal diffusivity $(\alpha)$ was measured by a laser flash technique using a Netzsch LFA447 thermal constant analyser. TC $(\lambda)$ of the composites was calculated using $\lambda=\alpha \rho C_{p}$, where $\rho$ and $C_{p}$ represent density and specific heat capacity, respectively. The heat capacity $\left(C_{p}\right)$ of the diamond/Al composite was calculated using the rule of mixtures and $C_{p}$ values of the constituents: $512 \mathrm{~J} / \mathrm{kg} \mathrm{K}$ for diamond particle [33] and $920 \mathrm{~J} / \mathrm{kg} \mathrm{K}$ for Al12Si matrix [34].

\subsection{Finite element analysis (FEA)}

To gain more insights into the SLM process, FEA was carried out to simulate the temperature evolution in the molten pool using the commercial $\mathrm{COMSOL}^{\mathrm{TM}}$ Multiphysics software. A numerical simulation of the heat transfer process was developed based on the interaction between the laser beam and powder bed. A simplified 2D symmetric model was used in order to reduce the calculation time, where the domains of powder bed $(30 \mu \mathrm{m} \times 150$ $\mu \mathrm{m})$, substrate $(250 \mu \mathrm{m} \times 150 \mu \mathrm{m})$ and gas atmosphere $(100 \mu \mathrm{m} \times 150 \mu \mathrm{m})$ were established. Assumptions were also made that fluid flow of A112Si within molten pool was Newtonian and 
incompressible. The porous powder bed was treated as a continuum media to simplify the simulation process. Table 1 lists the material properties of the A112Si and diamond particles used for the FEA.

Table 1: Thermal physics properties used for the FEA

\begin{tabular}{ll}
\hline Parameter & Value \\
\hline Laser absorptivity of Al12Si powder & $0.09[35]$ \\
Laser absorptivity of Diamond powder & $0.83[36]$ \\
Thermal conductivity of Al12Si powder & $173.8 \mathrm{~W} /(\mathrm{m} \cdot \mathrm{K})$ \\
Thermal conductivity of Diamond powder & $3320 \mathrm{~W} /(\mathrm{m} \cdot \mathrm{K})[37]$ \\
Specific heat of Al12Si powder & $920.0 \mathrm{~J} /(\mathrm{kg} \cdot \mathrm{K})$ \\
Specific heat of diamond powder & $630 \mathrm{~J} /(\mathrm{kg} \cdot \mathrm{K})$ \\
Melting temperature of Al12Si powder & $850 \mathrm{~K}$ \\
Melting temperature of diamond powder & $4300 \mathrm{~K}$ \\
\hline
\end{tabular}

The heat transfer in the computational domains of gas and powder bed can be expressed as:

$$
\rho C_{p} \frac{\partial T}{\partial t}+\rho C_{p} \vec{u} \cdot \nabla T+\nabla \cdot(-k \nabla T)=Q
$$

Where $\rho$ is the density $\left(\mathrm{kg} / \mathrm{m}^{3}\right), T$ is the temperature $(\mathrm{K}), C_{p}$ is the heat capacity $(\mathrm{J} /(\mathrm{Kg} \mathrm{K}))$, $k$ is the thermal conductivity $(\mathrm{W} /(\mathrm{m} \mathrm{K})), Q$ is the heat source term $\left(\mathrm{W} / \mathrm{m}^{2}\right)$.

At the gas-liquid interface, the heat source term in the energy conservation equation is composed by four parts: namely the laser energy input, the heat loss by mass evaporation, natural convection in building chamber and the surface-to-ambient radiation. The laser energy distribution at the gas-liquid interface boundary was treated as a Gaussian function.

$$
Q=Q_{\text {laser }}-Q_{\text {evap }}-Q_{\text {cov }}-Q_{\text {rad }}=\frac{2 A P}{\pi r_{0}^{2}} e^{\left(\frac{-2 x^{2}}{r_{0}^{2}}\right)}-\xi k_{B}\left(T_{0}^{4}-T^{4}\right)-H(T) \dot{m}-h\left(T-T_{0}\right)
$$

Where $A$ is the laser absorption of the powder bed system ( 0.09 for pure Al12Si), $P$ is the surface power density by laser input $\left(\mathrm{W} / \mathrm{m}^{2}\right), r_{0}$ is the radius of the laser spot $(40 \mu \mathrm{m}), H(T)$ is the enthalpy of the material by considering the latent heat of phase change, $\xi$ is the emissivity, $k_{b}$ is the Stefan-Boltzmann constant $\left(5.67 \times 10^{-8} \mathrm{~W} /\left(\mathrm{m}^{2} * \mathrm{~K}^{4}\right)\right)$. The heat loss which was a result of mass evaporation was calculated by the product between the enthalpy value and the 
vaporized mass flow rate. The latter was determined based on the vapour pressure as defined by the Maxwell-Boltzmann distribution, where the net vaporization rate is $88 \%$ of the equilibrium value [38].

$$
\dot{m} \approx 0.82 \dot{m}_{v}=0.88 p(T) \sqrt{\frac{m}{2 \pi k_{B} T}}
$$

\section{Results}

3.1 The effect of laser energy density on relative density, TC and interfacial thermal conductance (ITC)

As shown in Fig. 2a, there is the large difference in the required laser energy density for densifying the pure A112Si and diamond/A112Si composite samples. The lowest energy density used in this work $\left(59.5 \mathrm{~J} / \mathrm{mm}^{3}\right)$ results in near full densification of the pure Al12Si sample, while the relative density of the composite sample only reaches around $81 \%$. As the energy density increases (within the range of $95.2-158.7 \mathrm{~J} / \mathrm{mm}^{3}$ ), the relative density of the composite samples firstly increases and then reaches a plateau at around $90 \%$.

The TC as a function of laser energy density is shown in Fig. 2b. Compared with the fully dense Al12Si sample, which has a TC of around $119 \mathrm{~W} / \mathrm{m} \mathrm{K}$, all composite materials have lower TC, which is presumably a result of their lower densities. Among the composite samples, the samples printed using laser energy densities of 79.4 and $95.2 \mathrm{~J} / \mathrm{mm}^{3}$ had the highest TCs of around $93 \mathrm{~W} / \mathrm{m} \mathrm{K}$. The lower energy densities result in the lower densities (around $81 \%$ in Fig. 2a) and also low TCs (around $72 \mathrm{~W} / \mathrm{m} \mathrm{K}$ ). At high energies (119 and $158.7 \mathrm{~J} / \mathrm{mm}^{3}$ ), the samples have similarly low TCs of around $75 \mathrm{~W} / \mathrm{m} \mathrm{K}$, despite a higher relative density of around $90 \%$, which indicates that there are factors other than density controlling the TC. Fig. $2 \mathbf{c}$ shows the interfacial thermal conductance (ITC) between the diamond and Al12Si matrix, which was calculated using the differential effective medium (DEM) method that has been detailed in our previous work [23, 39]. As will be discussed below, the negative ITC values most probably 
originate from the fact that the value used in the calculations for the TC of the Al12Si matrix in the composites $(119 \mathrm{~W} / \mathrm{m} \mathrm{K})$ is an overestimate due to the microstructural changes in the matrix. However, the trend shown in Fig. $2 \mathbf{c}$ at least suggests that, at the relative density of around $90 \%$, the ITCs obtained using the medium laser energy densities of 79.4 and $95.2 \mathrm{~J} / \mathrm{mm}^{3}$ are much higher than those using the higher energy densities of 119 and $158.7 \mathrm{~J} / \mathrm{mm}^{3}$. Hence, the results of TC associated with relative density provides the hint that, despite the complex physical and chemical nature involved in the SLM process, it appears that the interface structure can be tailored which is comparable to conventional VHP and casting techniques. The underlying mechanisms for this tailoring will be discussed by investigating the microstructure of the composites processed at 95.2 and $119 \mathrm{~J} / \mathrm{mm}^{3}$, both having the very similar relative densities of around $90 \%$, but differing TCs and ITCs. In this case, the distinct TCs and ITCs are considered to be closely dependent on the nature of interface where its formation will be discussed relating to the complex metallurgical mechanisms of SLM.

\subsection{Microstructure characterization by XRD, SEM and TEM}

At the macroscopic scale, the XRD pattern recorded from the diamond/Al12Si composite processed at $95.2 \mathrm{~J} / \mathrm{mm}^{3}$ and pure Al12Si (at $59.5 \mathrm{~J} / \mathrm{mm}^{3}$ ) reveal the presence of additional diamond (111) and (220) peaks in the composite material. In contrast, the pure Al12Si pattern contains only $\mathrm{Al}$ and $\mathrm{Si}$ peaks (Figs. 3a and b). However, the presence of a small amount of $\mathrm{Al}_{4} \mathrm{C}_{3}$ is confirmed in the composite sample processed at the higher laser energy density of 119 $\mathrm{J} / \mathrm{mm}^{3}$ (Fig. 3c). Thus, it appears that the formation of $\mathrm{Al}_{4} \mathrm{C}_{3}$ by direct interfacial reaction between the diamond particles and Al matrix is limited (or even suppressed) during the SLM process at lower laser energy densities.

Interface characterization by SEM show very clear differences between composite samples at low $\left(95.2 \mathrm{~J} / \mathrm{mm}^{3}\right)$ and high $\left(119 \mathrm{~J} / \mathrm{mm}^{3}\right)$ energy densities (here on termed "low" and "high" energy density). At low energy density, a 'clean' diamond/Al interface is formed, which is 
devoid of reaction products like $\mathrm{Al}_{4} \mathrm{C}_{3}$ (Fig. 4). This result is consistent with the XRD pattern shown in Fig. 3b. In comparison, at the high energy density an O-rich interface layer that contains sub-micron sized particles, covers the diamond particle (Figs. 5 and 6). Oxygen-rich particles are also visible in the Al-Si matrix adjacent to the interface (Fig. 7). However, the nature of these interfacial particles cannot be determined due to limited spatial resolution of SEM. These small particles may also contain carbon, but the relative contrast in the interfacial area is likely to be masked by the presence of the very high carbon content diamond particles.

To further investigate the interface products, a FIB sample was extracted from the interface shown in Fig. 7a. The TEM results, Fig. 8, show that the high energy density results in an interfacial reaction at the diamond/Al interface to produce a tightly-bonded $\mathrm{Al}_{4} \mathrm{C}_{3}$ layer with inhomogeneous thickness, which varies from several tens of nanometres to a few hundred nanometres. Plate-like $\mathrm{Al}_{4} \mathrm{C}_{3}$ particles of several hundred nanometres in length are also observed in the $\mathrm{Al}$-Si matrix close to the interface. The different $\mathrm{Al}_{4} \mathrm{C}_{3}$ morphologies also indicate a different growth mechanism between the two forms. At the even higher magnification, an $\mathrm{O}$ - and $\mathrm{Al}$-rich interfacial layer (i.e. $\mathrm{Al}_{2} \mathrm{O}_{3}$ phase) with an average thickness of around 15 nm can be seen between the diamond particle and $\mathrm{Al}_{4} \mathrm{C}_{3}$ (Fig. 9).

There is a difference in the structure of the aluminium matrix between the pure Al12Si and composite material. Compared with the distribution of Si particles in the pure Al12Si sample (arrowed in Fig. 10b), the Si particles in the diamond/Al12Si composites form a more interconnected cell-like structure, and are approximately 60-80 $\mathrm{nm}$ in size (arrowed in Fig. 10a). The cells in the matrix of the composite material are approximately $150-300 \mathrm{~nm}$ in size, and contain fine Si nano precipitates $(<30 \mathrm{~nm})$. However, as confirmed by extensive EDX analyses (Figs. 10c-f), no such Si nano precipitates are detected in the pure Al12Si sample. In both composite samples, the large pores and cracks are often associated with the diamond particles (Fig. 11). It is also clear that the porosity is associated with O-rich areas. 


\subsection{Physical characteristics of the melt pool during SLM simulated by FEA}

The temperature distribution within the melt pool of the pure Al12Si (at $59.5 \mathrm{~J} / \mathrm{mm}^{3}$ ) and the composites processed at the low and high laser energy densities were modelled, and the result for the higher energy is shown in Fig. 12a, as an example. In order to understand the effect of the laser energy density on the interface evolution and microstructure formation, the variation in temperature and cooling rate of different areas along the central vertical direction (i.e. z-axis) away from the melt pool surface were extracted from the model and are plotted in Figs. 12b and c. Both the temperature and cooling rate reduce with increasing z-axis distance away from the liquid surface in the melt pool. The maximum temperature was calculated to be around 3600, 2344 and $2800 \mathrm{~K}$ for the pure Al12Si at $59.5 \mathrm{~J} / \mathrm{mm}^{3}$ and the composites at 95.2 and $119 \mathrm{~J} / \mathrm{mm}^{3}$ (Fig. 12b), respectively. In all the cases, the highest temperature, which is above or around the boiling point of Al12Si matrix of around $2800 \mathrm{~K}$, is found at the gas/liquid interface due to the direct interaction of high-energy laser beam.

Integration of 10 vol.\% diamond particles in the composites significantly reduces the temperature of the molten pool, which is mainly due to the enhanced energy dissipation caused by the higher TC of the intact diamond particles. Nonetheless, increasing the laser energy density does increase the temperature of the composite material.

Further, the raising laser energy density increases of the maximal cooling rate from around $1 \times 10^{5} \mathrm{~K} / \mathrm{s}$ in the pure A112Si to 1.5 and $3.8 \times 10^{5} \mathrm{~K} / \mathrm{s}$ in the composites (Fig. 12c). In addition to the influence of laser energy input on the cooling rates, the presence of diamond particles may also play a positive role on accelerating the cooling rates in the composites.

\section{Discussion}

\subsection{Metallurgical mechanisms of interface evaluation and microstructural formation}


It is thought that the absence of $\mathrm{Al}_{4} \mathrm{C}_{3}$ in the composite sample fabricated at $95.2 \mathrm{~J} / \mathrm{mm}^{3}$ is largely related to this being within the ideal processing window (Fig. 4). The reaction at the diamond/Al interface to form $\mathrm{Al}_{4} \mathrm{C}_{3}$ occurs with the reaction $4 \mathrm{Al}+3 \mathrm{C} \rightarrow \mathrm{Al}_{4} \mathrm{C}_{3}$. The energy formation for this reaction can be calculated approximately using

$$
\Delta \mathrm{G}_{\mathrm{f}}(\mathrm{kJ} / \mathrm{mol})=-266520+96.2 \mathrm{~T}(\mathrm{~K})[40]
$$

For example, at the maximum predicted temperatures of 2344 and $2800 \mathrm{~K}$ reached in the composites at two main laser energy densities (Fig. 12b), the $\Delta \mathrm{G}_{\mathrm{f}}$ values are -41027 and 2840 $\mathrm{kJ} / \mathrm{mol}$, respectively. Thus, the formation of $\mathrm{Al}_{4} \mathrm{C}_{3}$ only becomes thermodynamically unfavorable at very high temperatures $(>2770 \mathrm{~K})$, which seems not to support our results.

In addition, the very high cooling rate of the SLM process $\left(\sim 10^{5} \mathrm{~K} / \mathrm{sec}-\right.$ see Fig. 12c), results in the material cooling rapidly through the temperature range in which $\mathrm{Al}_{4} \mathrm{C}_{3}$ would be thermodynamically stable. However, it is well known that free $\mathrm{C}$ dissolution from the surface of diamond can greatly stimulate the nucleation and growth of $\mathrm{Al}_{4} \mathrm{C}_{3}$ [30]. The high peak temperature of $2800 \mathrm{~K}$ predicted for the composite sample built at $119 \mathrm{~J} / \mathrm{mm}^{3}$ (reaching around $74 \%$ of the melting temperature of diamond) is likely to result in more favorable conditions for carbon dissolution than at the lower laser energy density. It is assumed that Marangoni forces can then carry the diamond particles with dissolved $\mathrm{C}$ at the surface through the melt pool to areas of lower temperature away from the melt surface, resulting in the formation of $\mathrm{Al}_{4} \mathrm{C}_{3}$. Additionally, the melt pool is expected to stay hotter for longer time at laser energy density of $119 \mathrm{~J} / \mathrm{mm}^{3}$ when compared to the laser energy density of $95.2 \mathrm{~J} / \mathrm{mm}^{3}$. This higher temperature for longer time in the melt pool can also facilitate the reaction of the $\mathrm{Al}_{4} \mathrm{C}_{3}$, which together with the dissolved $\mathrm{C}$ in the $\mathrm{Al}$ matrix can counteract the abovementioned thermodynamic unfavorable factors.

A similar study of SLM-processed $\mathrm{SiC}(10$ vol.\%)/Al composite revealed that breakdown of the $\mathrm{SiC}$ particles (to form $\mathrm{Al}_{4} \mathrm{C}_{3}$ ) increased as the laser energy density increased, and no 
'clean' interface (similar to our results shown in Fig. 4) was able to be formed [16]. The main reason is that the physical characteristics of $\mathrm{SiC}$ are very different compared with those of the synthetic diamond used in this work. Specifically, the SiC has the much lower TC $(\sim 400 \mathrm{~W} / \mathrm{m}$ $\mathrm{K}$ compared with $1500-2500 \mathrm{~W} / \mathrm{m} \mathrm{K}$ for diamond) and lower melting temperature (3000 K vs. $3500 \mathrm{~K}$ for diamond). This means that the $\mathrm{SiC}$ is much more easily heated to high temperature, which aims the release of $\mathrm{C}$ atoms. For example, in the diamond/AlSi composite, $\mathrm{Al}_{4} \mathrm{C}_{3}$ was only present at energies above $95.2 \mathrm{~J} / \mathrm{mm}^{3}$. In contrast, in the $\mathrm{SiC} / \mathrm{AlSi}$ system, $\mathrm{Al}_{4} \mathrm{C}_{3}$ has been shown to form at an energy density of as low as $21 \mathrm{~J} / \mathrm{mm}^{3}[41]$.

The distribution of Si particles is very different in the composite samples compared with in the pure Al12Si sample (Fig. 10). The semi-quantitative EDX result confirms an extended solid-solubility of $\sim 4 \mathrm{wt} . \% \mathrm{Si}$ in the Al matrix of the composite, which is higher than that of $1.6 \mathrm{wt} . \%$ at the equilibrium state [6] and that of $2 \mathrm{wt} . \%$ which has been reported in melt spinning [42]. Similar results have been obtained in $\mathrm{SLMed} \mathrm{TiB}_{2} / \mathrm{AlSi} 10 \mathrm{Mg}$ composites, where the freeze-in of the supersaturated non-equilibrium Al and eutectic Al-Si at the cell boundaries have been determined to be dependent on rapid cooling rate and local compositions, respectively [43]. Accordingly, the higher Si content in the Al matrix (Fig. 10) indicate that the cooling rate in the diamond-containing composite is higher than in the pure Al12Si. This is further supported by the FEA results (Fig. 12c). This higher cooling rate is likely due to the higher laser energy densities and the presence of 10 vol.\% diamond, which is a very high thermal conductor. The formation of the inter-connected cell-like Si structure would also reduce the overall TC of the matrix due to the lower TC of Si of around $150 \mathrm{~W} / \mathrm{m} \mathrm{K}$ compared to that of pure $\mathrm{Al}(\sim 240 \mathrm{~W} / \mathrm{m}$ K). As detailed in Refs. [23, 39], at the given TC of the composite and volume fraction of the reinforcement (10 vol.\% in our case), the increase of the TC of the matrix systematically reduces the calculated ITC. Thus, without the measured TC of the Al12Si matrix available, the 
overestimated TC using that of the pure Al12Si sample for the calculations is probably cause of the negative ITC values in Fig. 2c.

Despite the use of a high purity argon atmosphere during the SLM process, the atmosphere contains some oxygen $(\sim 0.1 \%$ for these builds). As shown in both the SEM (Figs. 5-7) and TEM micrographs (Fig. 9), local formation of sub-micron sized $\mathrm{Al}_{2} \mathrm{O}_{3}$ particles and a nanoscaled $\mathrm{Al}_{2} \mathrm{O}_{3}$ interfacial layer has occurred, most likely by reaction with the atmospheric oxygen. However, this only occurred at the higher energy density. Analytical calculations have shown that the formation of an interfacial (crystallized or amorphous) $\mathrm{Al}_{2} \mathrm{O}_{3}$ layer or particles less than $30 \mathrm{~nm}$ has a limited effect on ITR and, in turn the overall TC of composite [29]. The detailed discussion of the underlying formation mechanism of the oxide is out of the scope of this work, but does deserve a more systematic study in the future. If the residual oxygen cannot be completely avoided during the SLM process, the microstructure (size, morphology and distribution, etc.) of the formed $\mathrm{Al}_{2} \mathrm{O}_{3}$ should be tailored in order to improve the overall mechanical and functional properties of the SLM-ed components.

\subsection{Porosity formation and possible solution for further densification}

It is apparent that the porosity is closely associated with oxygen-rich traces adjacent to the diamond particles (Fig. 11) and will significantly degrade the interfacial bonding state. The SLM process has not changed the shape of the diamond particles and thus we can conclude that they have not been melted. In contrast to $\mathrm{Al}_{2} \mathrm{O}_{3}$ interfacial layer formed as a result of oxygen pick-up (see section 4.1), the source of the oxides in this case is most probably the residual $\mathrm{Al}_{2} \mathrm{O}_{3}$ protective film from the starting $\mathrm{Al}$ powder. The reason for this is that it forms in the composite at both energy densities. The oxides also tend to orient along the build direction at the sides of the melt pool. This can be explained by the fact that Marangoni forces will tend to only break down the oxides at the bottom of the melt pool, while the oxides at the sides of the melt pool remains intact, creating regions with porosity [35]. The visible cracks surrounding 
the unmelted diamond particles are likely a result of the significant internal stresses generated during the rapid cooling due to the high difference of coefficient of thermal expansion between the diamond $\left(1.0 \times 10^{-6} \mathrm{~K}^{-1}\right)$ and the Al-Si matrix $\left(18 \times 10^{-6} \mathrm{~K}^{-1}\right)$. It is also clear that increasing the laser energy density has a very limited effect on further densification of the composite (Fig. 1a). Simultaneously, the harmful effect of the high energy density, decreases the overall TC due to excessive interfacial reactions and oxygen pick-up (Figs. 5-9).

As previously reported by theoretical calculations [39] and experimental validation [24], deposition of a nanosized layer containing carbide-forming metals (e.g. Cr, W, Mo or Ti) or their carbides on the surface of the diamond particles can be beneficial for TC enhancement. These coated powders can not only impede the formation of brittle $\mathrm{Al}_{4} \mathrm{C}_{3}$ whose kinetics are difficult to controlled at elevated temperature, but also facilitate the formation of a strong chemical bonding. However, the laser high absorptivity of the carbides is a concern during the SLM process, where the introduction of nanosized $\mathrm{WC}$ and $\mathrm{TiC}$ layers may produce localized high temperature regions due to their high absorptivity of around 0.82 (at the wave length of $1.06 \mu \mathrm{m})$ [38]. The use of coated powder could facilitate the formation of a strongly bonded multi-layered interface, which would act to minimize the risk of cracking and increase ITC. In addition, the use of a pre-alloyed, gas-atomized diamond/Al12Si composite powder of $\sim 30 \mu \mathrm{m}$ in size should have good flowability and a homogenous laser-powder interaction. Hence, proper surface modification of diamond particles and synthesis of a new pre-alloyed composite powder would be a more feasible strategy for allowing further densification and interface tailoring. Finally, it is not known if the commercially available A112Si is a suitable matrix for incorporating hard second-phase diamond particles for SLM. Specific material development will also be the main issue for further development of heterogeneous composite materials.

\section{Conclusions and remarks}


Net-shape manufacturing of a diamond/Al (or Al alloy) composite with a high $\mathrm{TC}$ is desirable for thermal management applications in the microelectronics industry. However, due to the poor machinability of the hard diamond, additive manufacturing processes such as SLM provide significant advantages due to its ability to form complex, net-shaped components. Previous work has demonstrated that acquiring both full density and a diffusion-bonded interface (i.e. a 'clean' (without the $\mathrm{Al}_{4} \mathrm{C}_{3}$ formation) and tightly-adhered interface characterized by SEM) is necessary for enhancing the overall TC of composite [29]. Thus, this work creates a step forward in exploring the feasibility of SLM to reach these challenging objectives using the diamond (10 vol.\%)/A112Si powder mixture. By appropriate optimization of the laser energy density $\left(95 \mathrm{~J} / \mathrm{mm}^{3}\right.$ in this case), a high-quality 'clean' diffusion-bonded interface was shown to form, which demonstrates the potential of SLM for creating highperformance MMCs for functional applications. Compared with SLM of commercially available $\mathrm{Al}$ and Ti alloys, the production of near fully dense diamond/Al12Si composites via SLM still remains a key technical issue and will require additional systematic investigations. Surface metallization of diamond particles using carbides having high absorptivity, such as TiC or WC, and synthesis of gas-atomized pre-alloyed diamond/Al12Si composite powder are suggested as the possible strategies for reducing porosity while minimizing TC loss.

\section{Acknowledgement}

This work was partially supported by the Flemish Agency for Innovation by Science and Technology (IWT) Strategic Basic Research (SBO) project "MultiMet". G. Ji would like to thank the PHC French-Chinese collaboration project "XU Guangqi" (No. 38704RB) and the 2016 Gledden visiting fellowship provided by the University of Western Australia. Y. Ma is grateful for his Ph.D. project supported by the China Scholarship Council (Grant No. 201606230212). Thanks are also due to M. Florent Blanchard and Dr. Pascal Roussel (UCCS, 
Université de Lille) for their assistance of XRD experiments. The TEM facility in Lille, France, is supported by the Conseil Regional du Nord-Pas de Calais and the European Regional Development Fund (ERDF).

\section{References}

[1] D. Bourell, J.P. Kruth, M. Leu, G. Levy, D. Rosen, A.M. Beese, A. Clare, Materials for additive manufacturing, CIRP Annals-Manufacturing Technology 66 (2017) 659-681.

[2] J.-P. Kruth, M.-C. Leu, T. Nakagawa, Progress in additive manufacturing and rapid prototyping, CIRP Annals-Manufacturing Technology 47 (1998) 525-540.

[3] J.-P. Kruth, G. Levy, F. Klocke, T. Childs, Consolidation phenomena in laser and powderbed based layered manufacturing, CIRP Annals-Manufacturing Technology 56 (2007) 730-759. [4] G.N. Levy, R. Schindel, J.-P. Kruth, Rapid manufacturing and rapid tooling with layer manufacturing (LM) technologies, state of the art and future perspectives, CIRP AnnalsManufacturing Technology 52 (2003) 589-609.

[5] D. Gu, W. Meiners, K. Wissenbach, R. Poprawe, Laser additive manufacturing of metallic components: materials, processes and mechanisms, International materials reviews 57 (2012) $133-164$

[6] T. Sercombe, X. Li, Selective laser melting of aluminium and aluminium metal matrix composites, Materials Technology 31 (2016) 77-85.

[7] J. Zhang, B. Song, Q. Wei, D. Bourell, Y. Shi, A review of selective laser melting of aluminum alloys: processing, microstructure, property and developing trends, Journal of Materials Science \& Technology 35 (2019) 270-284.

[8] X. Li, X. Wang, M. Saunders, A. Suvorova, L. Zhang, Y. Liu, M. Fang, Z. Huang, T.B. Sercombe, A selective laser melting and solution heat treatment refined Al-12Si alloy with a 
controllable ultrafine eutectic microstructure and 25\% tensile ductility, Acta Materialia 95 (2015) 74-82.

[9] J. Wu, X. Wang, W. Wang, M. Attallah, M. Loretto, Microstructure and strength of selectively laser melted AlSi10Mg, Acta Materialia 117 (2016) 311-320.

[10] M. Wang, B. Song, Q. Wei, Y. Zhang, Y. Shi, Effects of annealing on the microstructure and mechanical properties of selective laser melted AlSi7Mg alloy, Materials Science and Engineering: A 739 (2019) 463-472.

[11] P. Wang, C. Gammer, F. Brenne, K.G. Prashanth, R.G. Mendes, M.H. Rümmeli, T. Gemming, J. Eckert, S. Scudino, Microstructure and mechanical properties of a heat-treatable Al-3.5 $\mathrm{Cu}-1.5 \mathrm{Mg}-1 \mathrm{Si}$ alloy produced by selective laser melting, Materials Science and Engineering: A 711 (2018) 562-570.

[12] J.H. Martin, B.D. Yahata, J.M. Hundley, J.A. Mayer, T.A. Schaedler, T.M. Pollock, 3d printing of high-strength aluminium alloys, Nature 549 (2017) 365-369.

[13] S.K. Ghosh, P. Saha, Crack and wear behavior of SiC particulate reinforced aluminium based metal matrix composite fabricated by direct metal laser sintering process, Materials \& Design 32 (2011) 139-145.

[14] P. Wang, L. Deng, K. Prashanth, S. Pauly, J. Eckert, S. Scudino, Microstructure and mechanical properties of $\mathrm{Al}-\mathrm{Cu}$ alloys fabricated by selective laser melting of powder mixtures, Journal of Alloys and Compounds 735 (2018) 2263-2266.

[15] D. Gu, H. Wang, D. Dai, P. Yuan, W. Meiners, R. Poprawe, Rapid fabrication of Al-based bulk-form nanocomposites with novel reinforcement and enhanced performance by selective laser melting, Scripta Materialia 96 (2015) 25-28.

[16] X. Li, C. Kong, T. Becker, T. Sercombe, Investigation of interfacial reaction products and stress distribution in selective laser melted $\mathrm{A} 112 \mathrm{Si} / \mathrm{SiC}$ composite using confocal Raman microscopy, Advanced Engineering Materials 18 (2016) 1337-1341. 
[17] N. Kang, Y. Fu, P. Coddet, B. Guelorget, H. Liao, C. Coddet, On the microstructure, hardness and wear behavior of Al-Fe-Cr quasicrystal reinforced Al matrix composite prepared by selective laser melting, Materials \& Design 132 (2017) 105-111.

[18] L. Jiang, T. Liu, C. Zhang, K. Zhang, M. Li, T. Ma, W. Liao, Preparation and mechanical properties of CNTs-AlSi10Mg composite fabricated via selective laser melting, Materials Science and Engineering: A 734 (2018) 171-177.

[19] Q. Han, R. Setchi, S.L. Evans, Synthesis and characterisation of advanced ball-milled AlAl 2 O 3 nanocomposites for selective laser melting, Powder Technology 297 (2016) 183-192. [20] D. Dai, D. Gu, M. Xia, C. Ma, H. Chen, T. Zhao, C. Hong, A. Gasser, R. Poprawe, Melt spreading behavior, microstructure evolution and wear resistance of selective laser melting additive manufactured AlN/AlSi10Mg nanocomposite, Surface and Coatings Technology 349 (2018) 279-288.

[21] P. Ball, Feeling the heat, Nature 492 (2012) 174.

[22] W.B. Johnson, B. Sonuparlak, Diamond/Al metal matrix composites formed by the pressureless metal infiltration process, Journal of materials research 8(5) (1993) 1169-1173.

[23] Z. Tan, Z. Li, G. Fan, X. Kai, G. Ji, L. Zhang, D. Zhang, Fabrication of diamond/aluminum composites by vacuum hot pressing: process optimization and thermal properties, Composites Part B: Engineering 47 (2013) 173-180.

[24] Z. Tan, Z. Li, G. Fan, Q. Guo, X. Kai, G. Ji, L. Zhang, D. Zhang, Enhanced thermal conductivity in diamond/aluminum composites with a tungsten interface nanolayer, Materials \& Design 47 (2013) 160-166.

[25] I. Monje, E. Louis, J. Molina, Optimizing thermal conductivity in gas-pressure infiltrated aluminum/diamond composites by precise processing control, Composites Part A: Applied Science and Manufacturing 48 (2013) 9-14. 
[26] I. Monje, E. Louis, J. Molina, On critical aspects of infiltrated Al/diamond composites for thermal management: Diamond quality versus processing conditions, Composites Part A: Applied Science and Manufacturing 67 (2014) 70-76.

[27] Z. Che, Y. Zhang, J. Li, H. Zhang, X. Wang, C. Sun, J. Wang, M.J. Kim, Nucleation and growth mechanisms of interfacial Al $4 \mathrm{C} 3$ in Al/diamond composites, Journal of Alloys and Compounds 657 (2016) 81-89.

[28] G. Ji, Z. Tan, Y. Lu, D. Schryvers, Z. Li, D. Zhang, Heterogeneous interfacial chemical nature and bonds in a W-coated diamond/Al composite, Materials Characterization 112 (2016) $129-133$.

[29] Z. Tan, G. Ji, A. Addad, Z. Li, J.-F. Silvain, D. Zhang, Tailoring interfacial bonding states of highly thermal performance diamond/Al composites: Spark plasma sintering vs. vacuum hot pressing, Composites Part A: Applied Science and Manufacturing 91 (2016) 9-19.

[30] S. Kleiner, F. Khalid, P. Ruch, S. Meier, O. Beffort, Effect of diamond crystallographic orientation on dissolution and carbide formation in contact with liquid aluminium, Scripta Materialia 55(4) (2006) 291-294.

[31] M. Wong, S. Tsopanos, C.J. Sutcliffe, I. Owen, Selective laser melting of heat transfer devices, Rapid Prototyping Journal 13 (2007) 291-297.

[32] A. Simchi, Direct laser sintering of metal powders: mechanism, kinetics and microstructural features, Materials Science and Engineering: A 428 (2006) 148-158.

[33] H. Feng, J. Yu, W. Tan, Microstructure and thermal properties of diamond/aluminum composites with TiC coating on diamond particles, Materials chemistry and physics 124 (2010) $851-855$

[34] B. Angadi, C. Hiremath, A. Reddy, V. Katti, S. Kori, Studies on the Thermal Properties of Hypereutectic Al-Si Alloys by Using Transient Method, Journal of Mechanical Engineering 2(1) (2014) 536-544. 
[35] E. Louvis, P. Fox, C.J. Sutcliffe, Selective laser melting of aluminium components, Journal of Materials Processing Technology 211 (2011) 275-284.

[36] CRC handbook of chemistry and physics, in W.M. Haynes (Eds.), CRC press, 2014.

[37] Y.-J. Chen, T.-F. Young, Thermal stress and heat transfer characteristics of a $\mathrm{Cu} /$ diamond/Cu heat spreading device, Diamond and Related Materials 18 (2009) 283-286.

[38] S. Anisimov, Vaporization of metal absorbing laser radiation, in I.M. Khalatnikov, V.P. Mineev (Eds.), 30 Years Of The Landau Institute-Selected Papers, World Scientific, 1996, pp. 14-15.

[39] Z. Tan, Z. Li, D.-B. Xiong, G. Fan, G. Ji, D. Zhang, A predictive model for interfacial thermal conductance in surface metallized diamond aluminum matrix composites, Materials \& Design 55 (2014) 257-262.

[40] R.Y. Lin, Interface evolution in aluminum matrix composites during fabrication, Key Engineering Materials, 104-107 (1995) 507-522.

[41] L.C. Astfalck, G.K. Kelly, X. Li, T.B. Sercombe, On the breakdown of SiC during the selective laser melting of aluminum matrix composites, Advanced Engineering Materials 19 (2017) 1600835.

[42] Z. Chen, Y. Lei, H. Zhang, Structure and properties of nanostructured A357 alloy produced by melt spinning compared with direct chill ingot, Journal of Alloys and Compounds 509 (2011) $7473-7477$

[43] X. Li, G. Ji, Z. Chen, A. Addad, Y. Wu, H. Wang, J. Vleugels, J. Van Humbeeck, J.-P. Kruth, Selective laser melting of nano-TiB2 decorated AlSi10Mg alloy with high fracture strength and ductility, Acta Materialia 129 (2017) 183-193. 


\section{Figure Captions}

Figure 1: Secondary-electron (SE) SEM images showing the morphologies of the starting (a) diamond and (b) Al12Si powders. In (c), as-built samples are shown.

Figure 2: (a) Relative density and (b) TC of the pure Al12Si (arrowed) and diamond/Al12Si composite samples as a function of laser energy density and (c) ITC of the composites back calculated from the measured TCs by considering relative density.

Figure 3: XRD patterns of the (a) pure Al12Si and diamond/Al12Si composite samples processed using the different laser energy densities of (b) 95.2 and (c) $119 \mathrm{~J} / \mathrm{mm}^{3}$. Stars denote the $\mathrm{Al}(111)$ and $\mathrm{Al}(200) \mathrm{k}_{\beta}$ peaks at 34.62 and $40.20^{\circ}$, respectively. The inset is a magnification of the box area in (c) and shows more clearly the presence of the $\mathrm{Al}_{4} \mathrm{C}_{3}$ peaks (JCPDS file 350799).

Figure 4: (a) SE SEM image of the diamond/Al composite processed using the low laser energy density $\left(95.2 \mathrm{~J} / \mathrm{mm}^{3}\right)$. In (b) a high-magnification backscattered-electron (BSE) SEM image of the region indicated by the box in (a) is shown. Elemental maps of the area in (b) is shown in (c)-(f) for $\mathrm{C}, \mathrm{O}, \mathrm{Al}$ and $\mathrm{Si}$, respectively. It is apparent that there is a clear interface.

Figure 5: (a) SE and (b) BSE SEM images of the diamond/Al composite processed using the high laser energy density $\left(119 \mathrm{~J} / \mathrm{mm}^{3}\right)$. These show the diamond/Al interface of a whole diamond particle in the composite sample. Elemental maps of the area is shown in (c)-(f) $\mathrm{C}, \mathrm{O}$, $\mathrm{Al}$ and $\mathrm{Si}$, respectively. There is an oxygen rich interface layer, which is most clearly seen in the lower left of diamond particle in (d).

Figure 6: (a) High-magnification SE SEM image of box No. 1 in Fig. 5a showing an interface layer covering the diamond/Al interface, (b) EDX spectrum of the interfacial layer and (c)-(f) EDX elemental maps of $\mathrm{C}, \mathrm{O}, \mathrm{Al}$ and $\mathrm{Si}$, respectively. It is apparent that this layer consists of oxide particles of some form. 
Figure 7: (a) High-magnification SE SEM image of box No. 2 in Fig. 5a showing particles within the Al-Si matrix adjacent to the interface. The EDX spectrum, (b) and elemental maps, (c)-(f) indicate that these too are some form of oxide.

Figure 8: (a) Scanning TEM (STEM) high-angle annular dark-field (HAADF) image showing the diamond $(111) / \mathrm{Al}$ interfacial area where $\mathrm{Al}_{4} \mathrm{C}_{3}$ interfacial layer and plate-like particles are developed. In (b) the EDX spectrum of a typical interfacial particle is shown. (c)-(f) are elemental EDX maps for Al, O, Si and C, respectively. The dotted line indicates the diamond/Al interface and inset in (b) is the [100] zone axis pattern of $\mathrm{Al}_{4} \mathrm{C}_{3}$. Homogenous $\mathrm{O}$ distribution in the Al matrix most probably originates from oxidation of the FIB sample.

Figure 9: (a) STEM-HAADF image showing the diamond(111)/Al interfacial area where a diamond ${ }_{(111)} / \mathrm{Al}_{2} \mathrm{O}_{3} / \mathrm{Al}_{4} \mathrm{C}_{3}$ multi interfacial layer can be seen. In (b)-(d) the corresponding $\mathrm{Al}$, $\mathrm{O}$ and $\mathrm{C}$ elemental EDX maps are shown, respectively. The individual EDX spectra shown in (e) to (g), correspond to the diamond, $\mathrm{Al}_{2} \mathrm{O}_{3}$ and $\mathrm{Al}_{4} \mathrm{C}_{3}$.

Figure 10: TEM bright-field images showing the distribution of Si particles in the (a) matrix of the composite sample (laser energy density of $95.2 \mathrm{~J} / \mathrm{mm}^{3}$ ) and (b) the pure Al12Si sample; (c) and (d) EDX spectra associated with semi quantitative results corresponding to the Al matrix and Si particles in (a), respectively; (e) and (f) EDX spectra associated with semi quantitative results corresponding to the $\mathrm{Al}$ matrix and $\mathrm{Si}$ particles in (b), respectively. The inset in (a) highlights Si particles inside the Al matrix. Peaks of Ga in (c) and (d) originate from the effect of FIB preparation. Also note that both the characterized composite samples displayed the same cell-like Si particle (arrowed) distribution, which is different from that of the pure Al12Si sample.

Figure 11: (a) SE SEM image showing typical porosities revealed in both SLM-ed composite samples processed at 95.2 and $119 \mathrm{~J} / \mathrm{mm}^{3}$ and (b), (c), (d) and (e) corresponding C, O, Al and Si EDX elemental maps, respectively. Arrow in (a) indicates the building direction. 
Figure 12: (a) Simulated temperature distribution in the composite sample processed at a laser energy density of $119 \mathrm{~J} / \mathrm{mm}^{3}$. In (b) and (c) the temperature and cooling rate as a function of the distance along z-axis away from melt pool surface is shown, respectively.
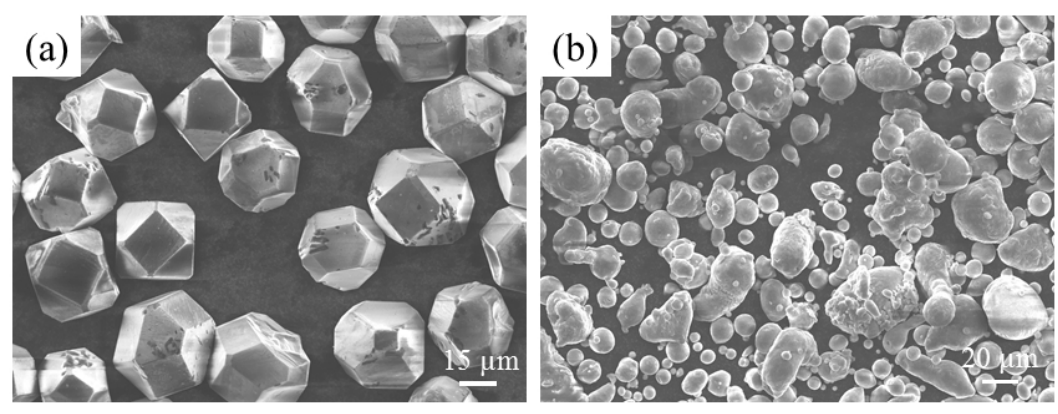

(c)

\section{Figure 1}
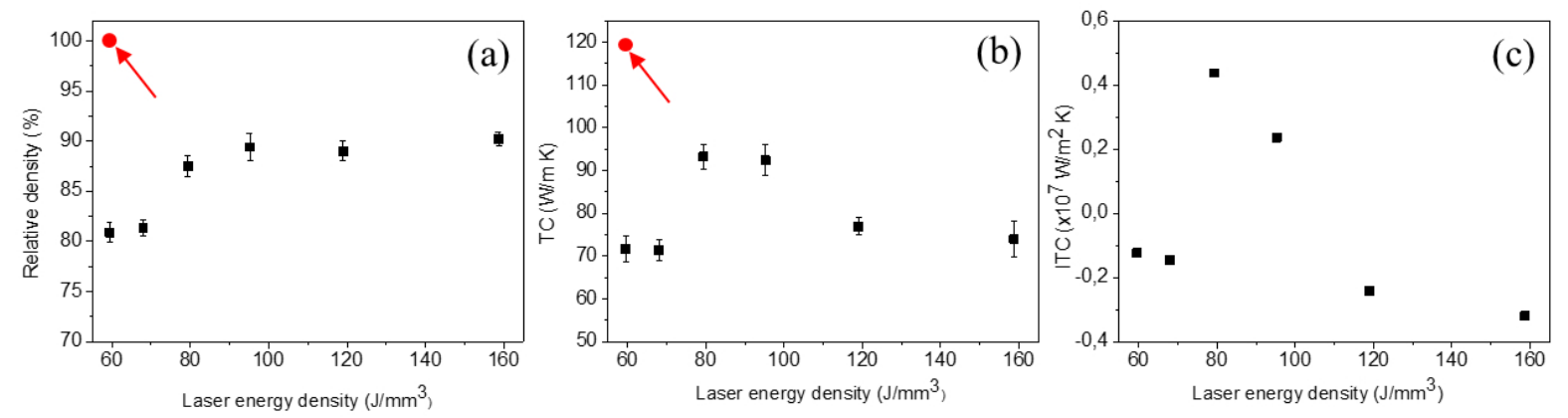

\section{Figure 2}




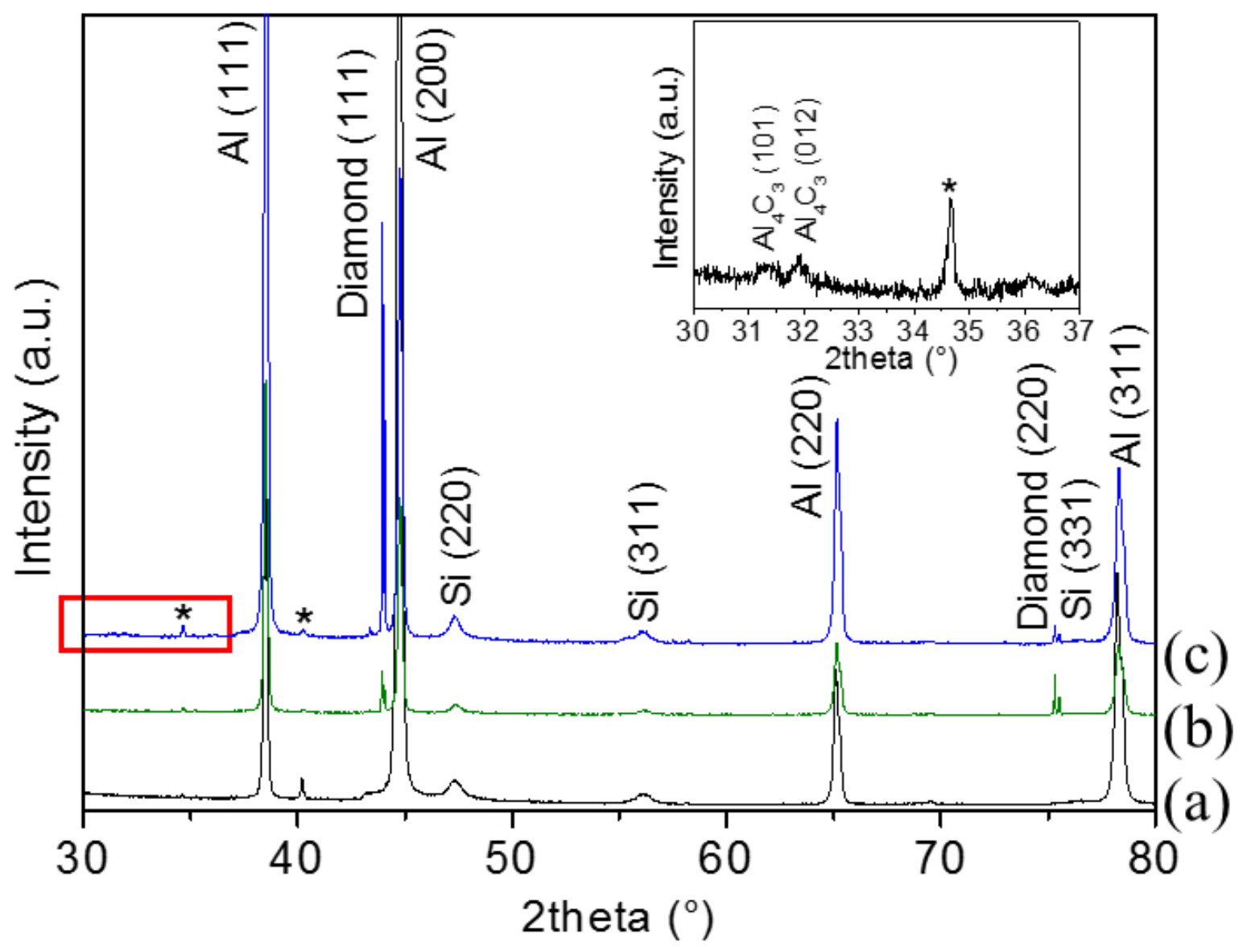

Figure 3

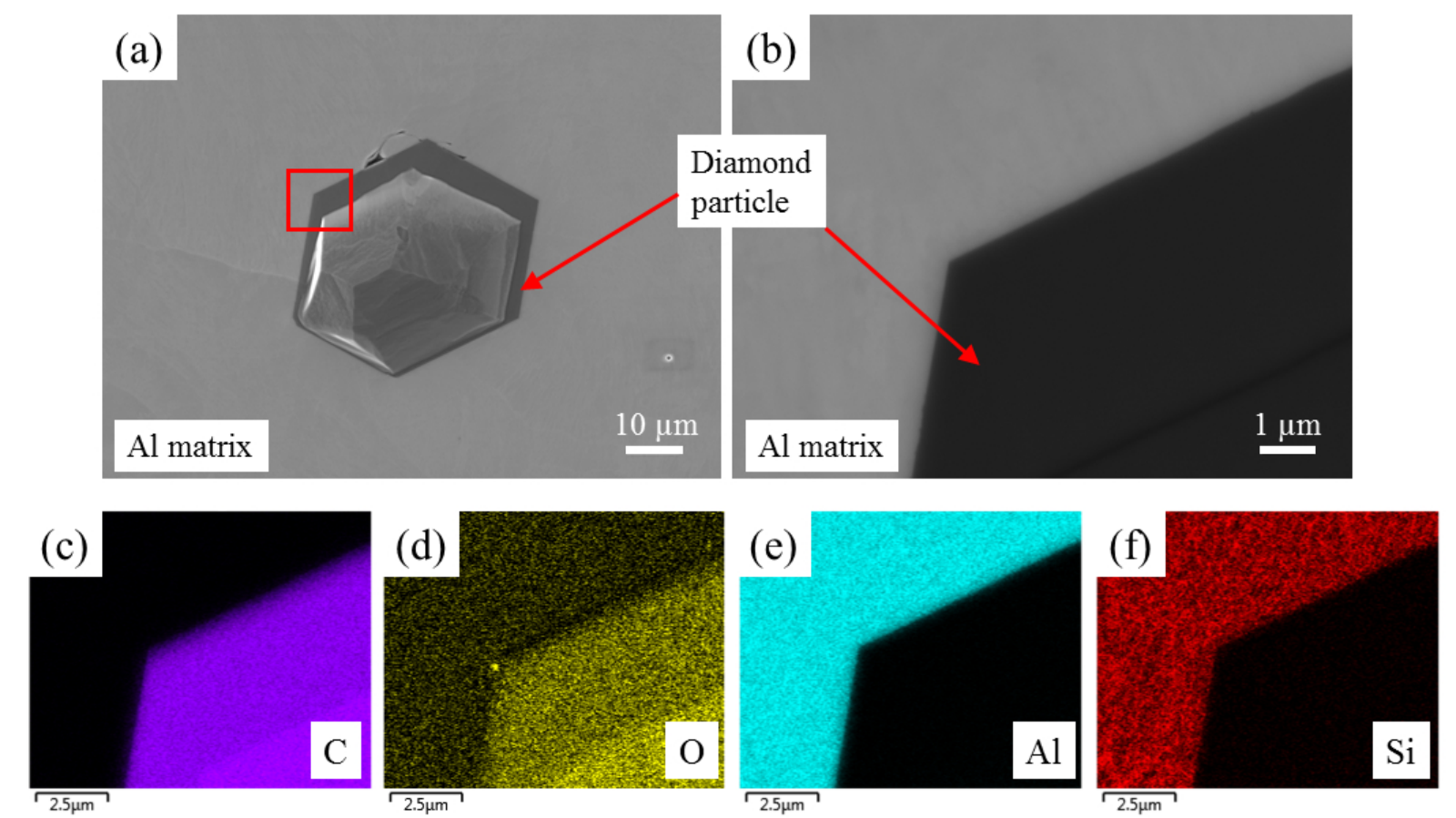

Figure 4 

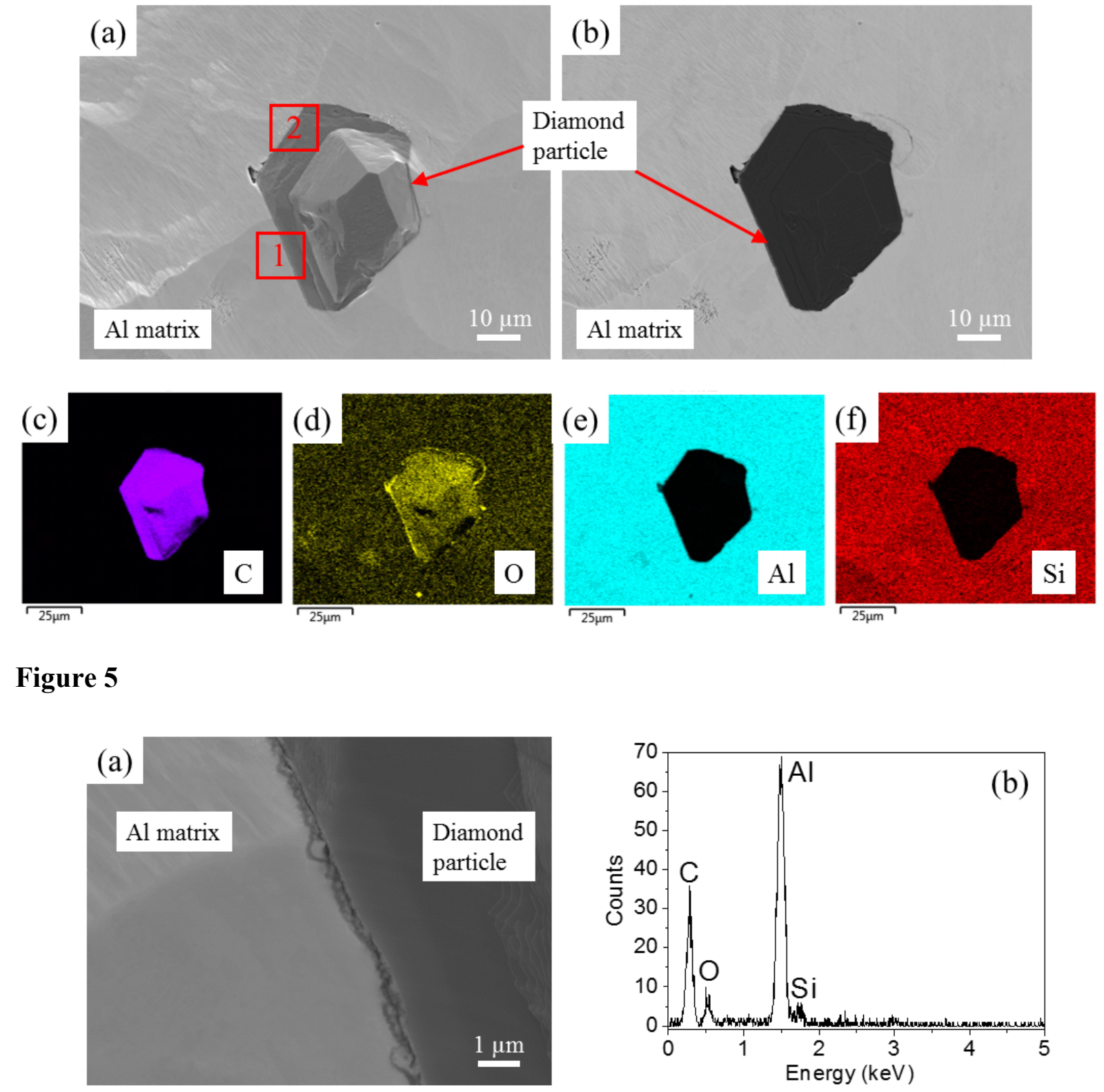

\section{Figure 5}
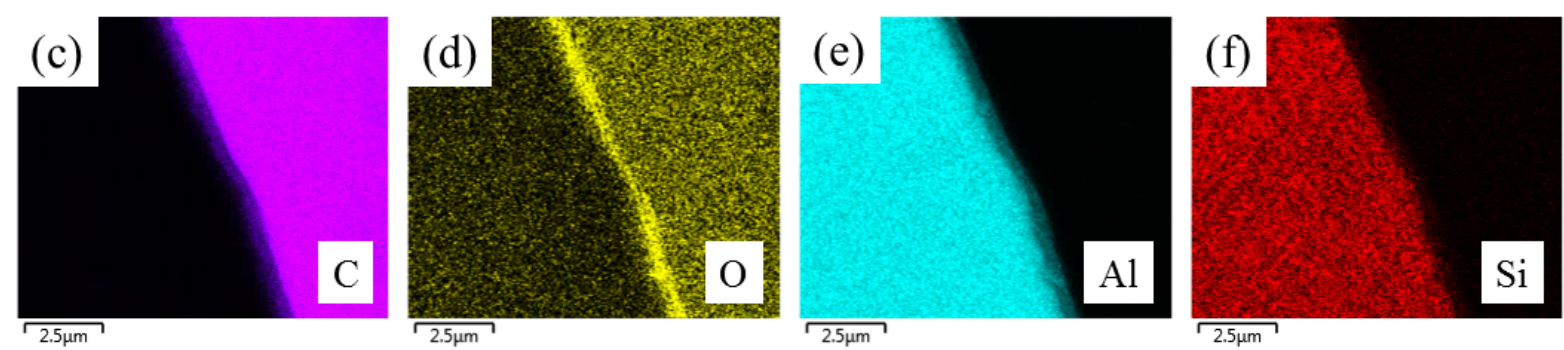

Figure 6 

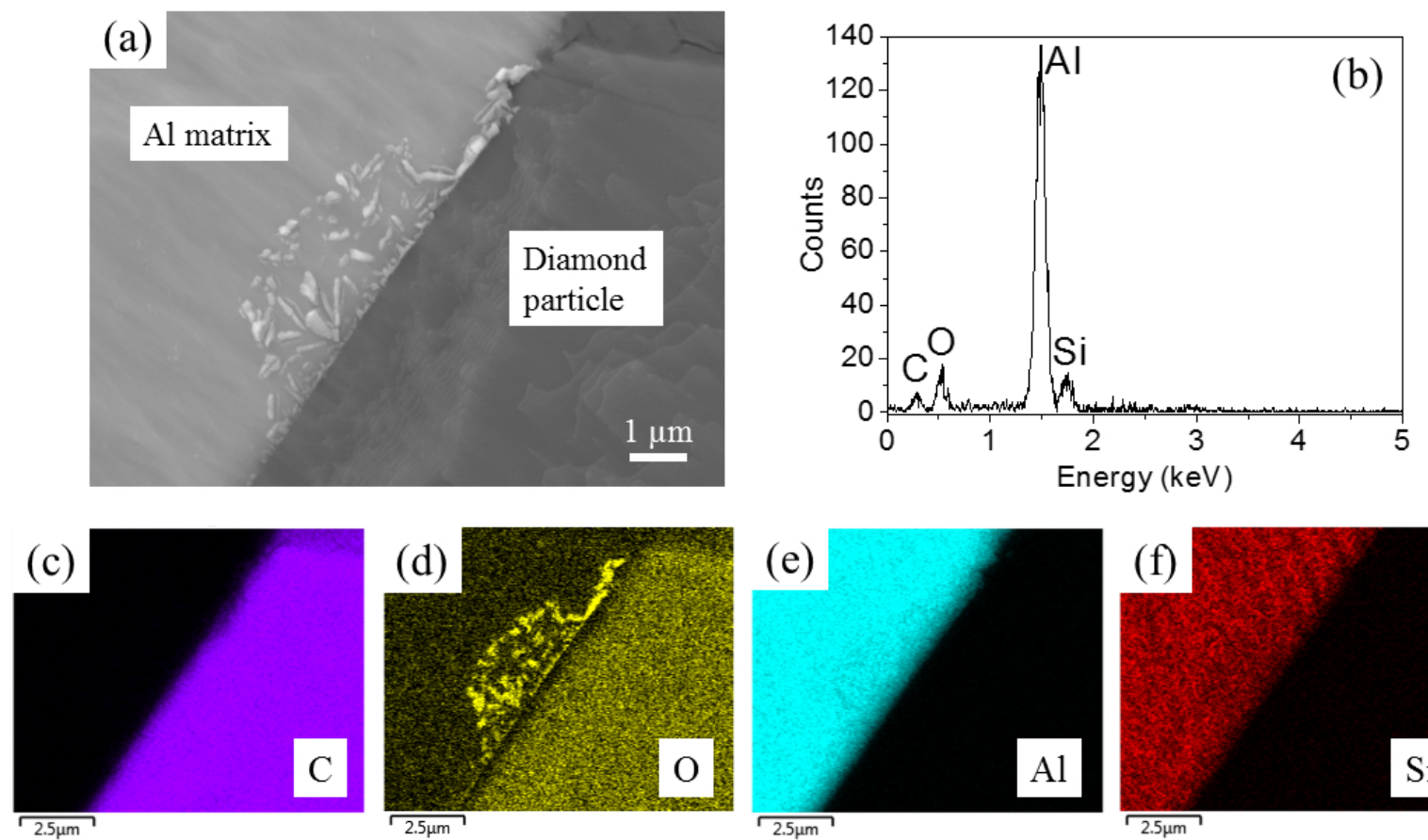

(f)

Figure 7 

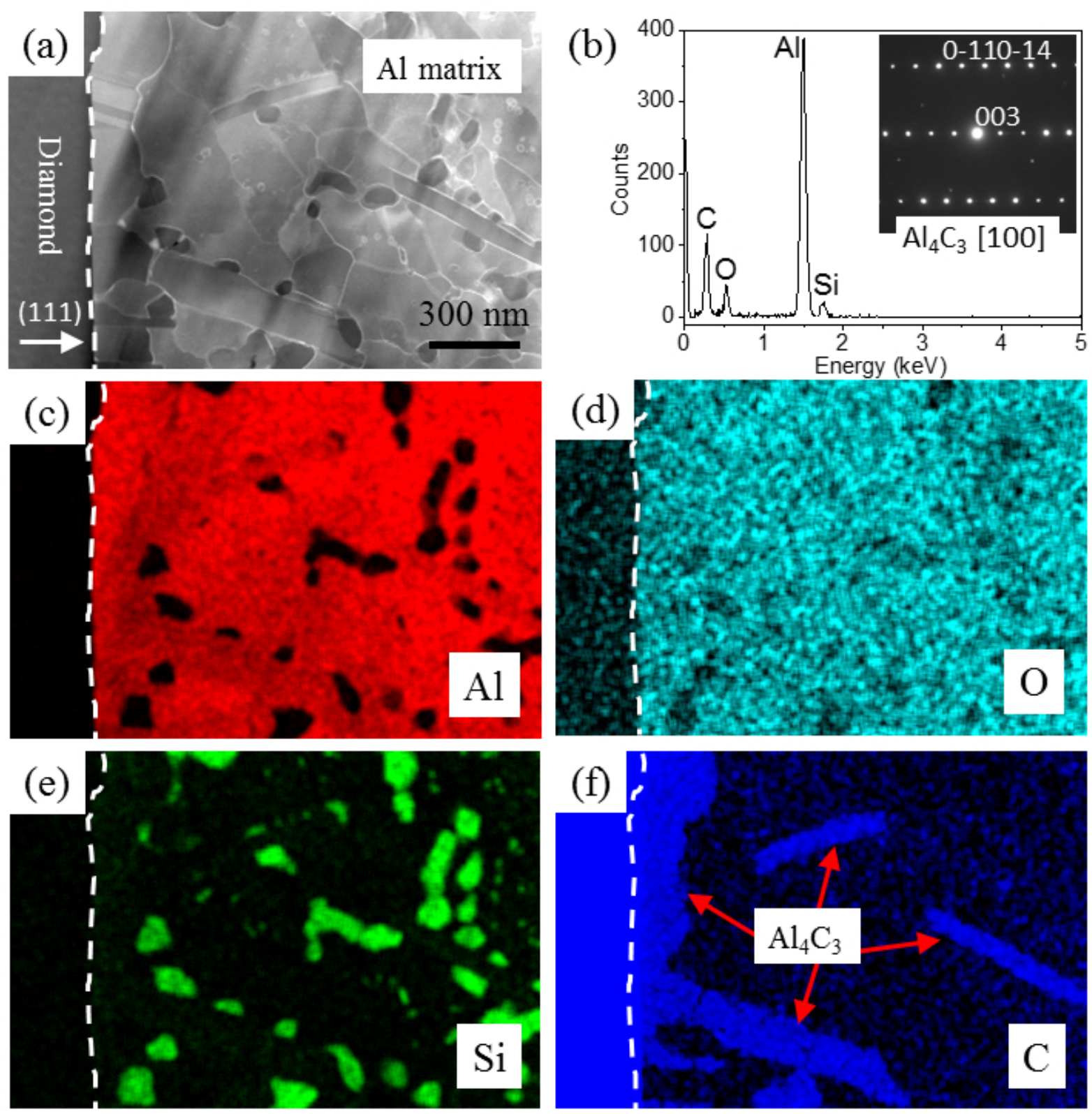

Figure 8 


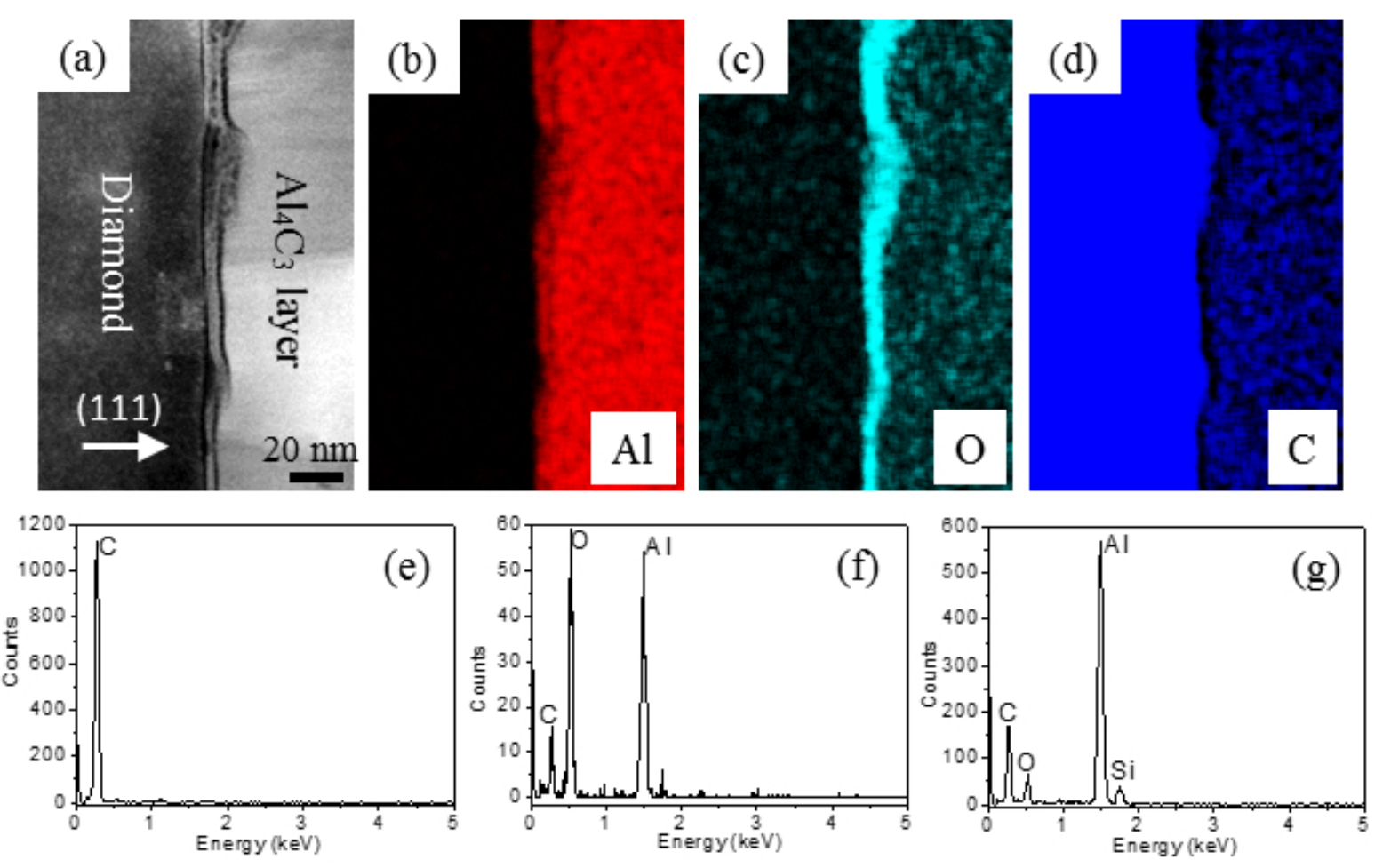

Figure 9 

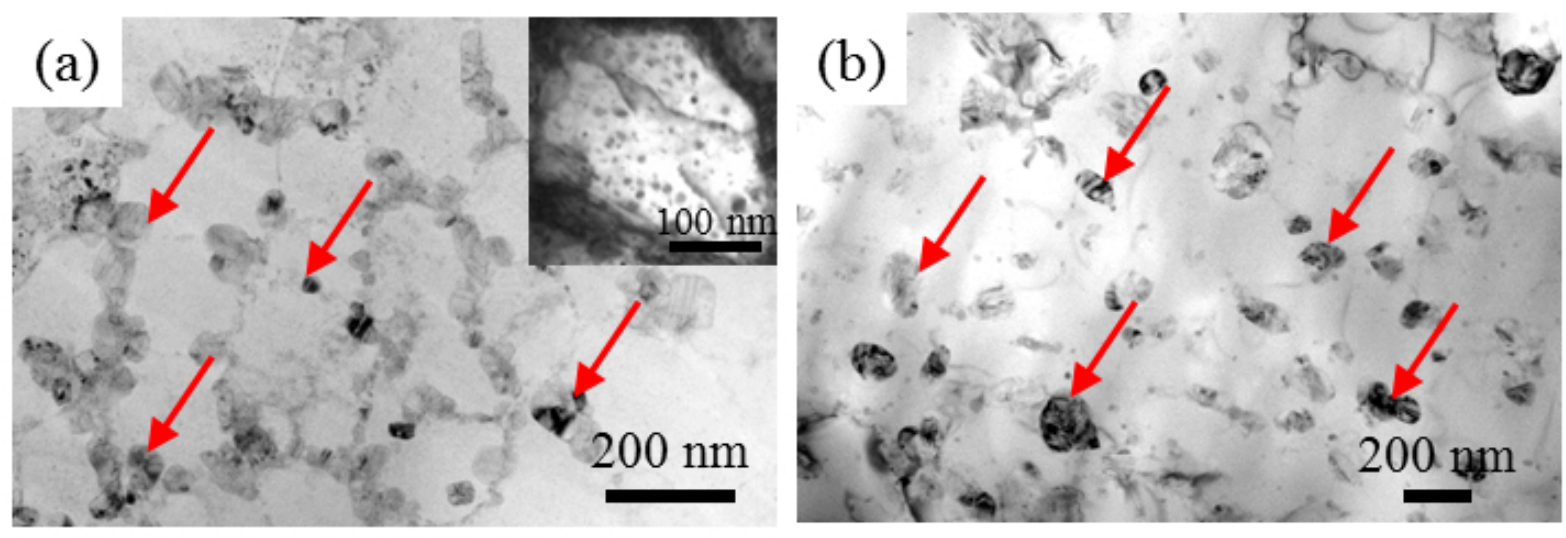

(c)

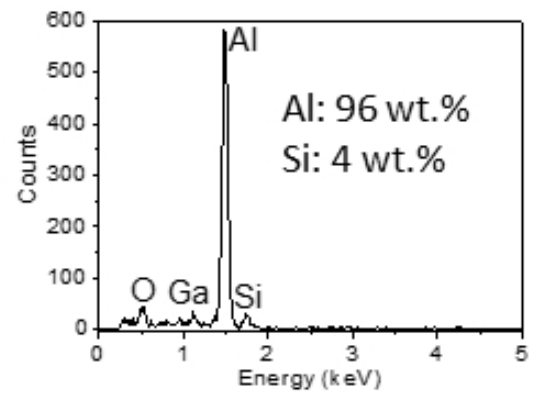

(d)

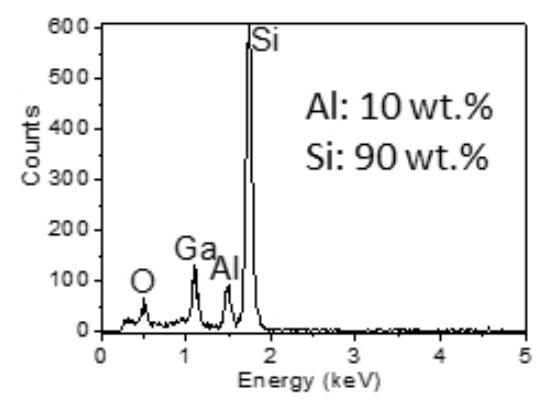

(e)

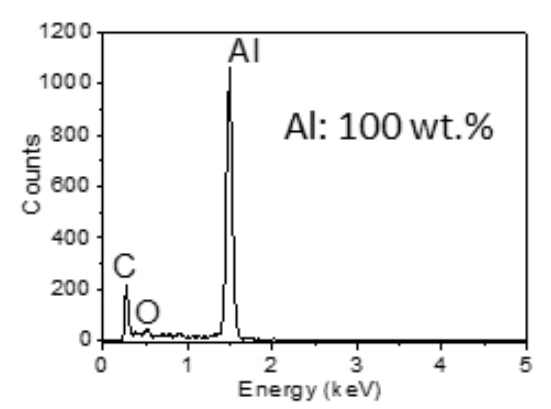

(f)

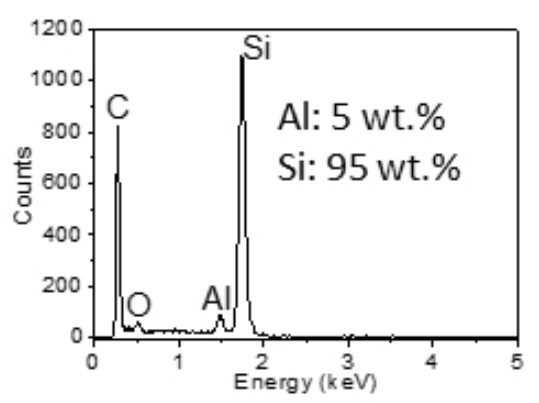

Figure 10
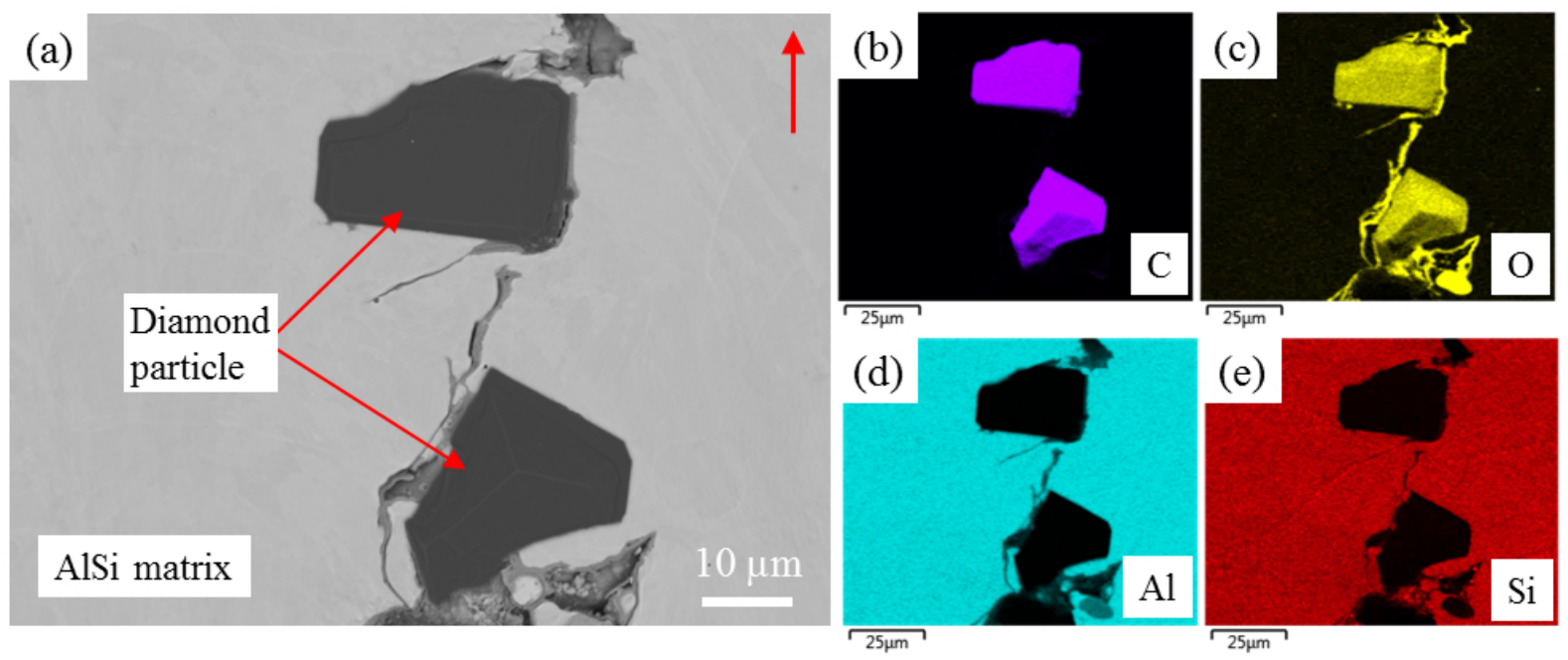

Figure 11 


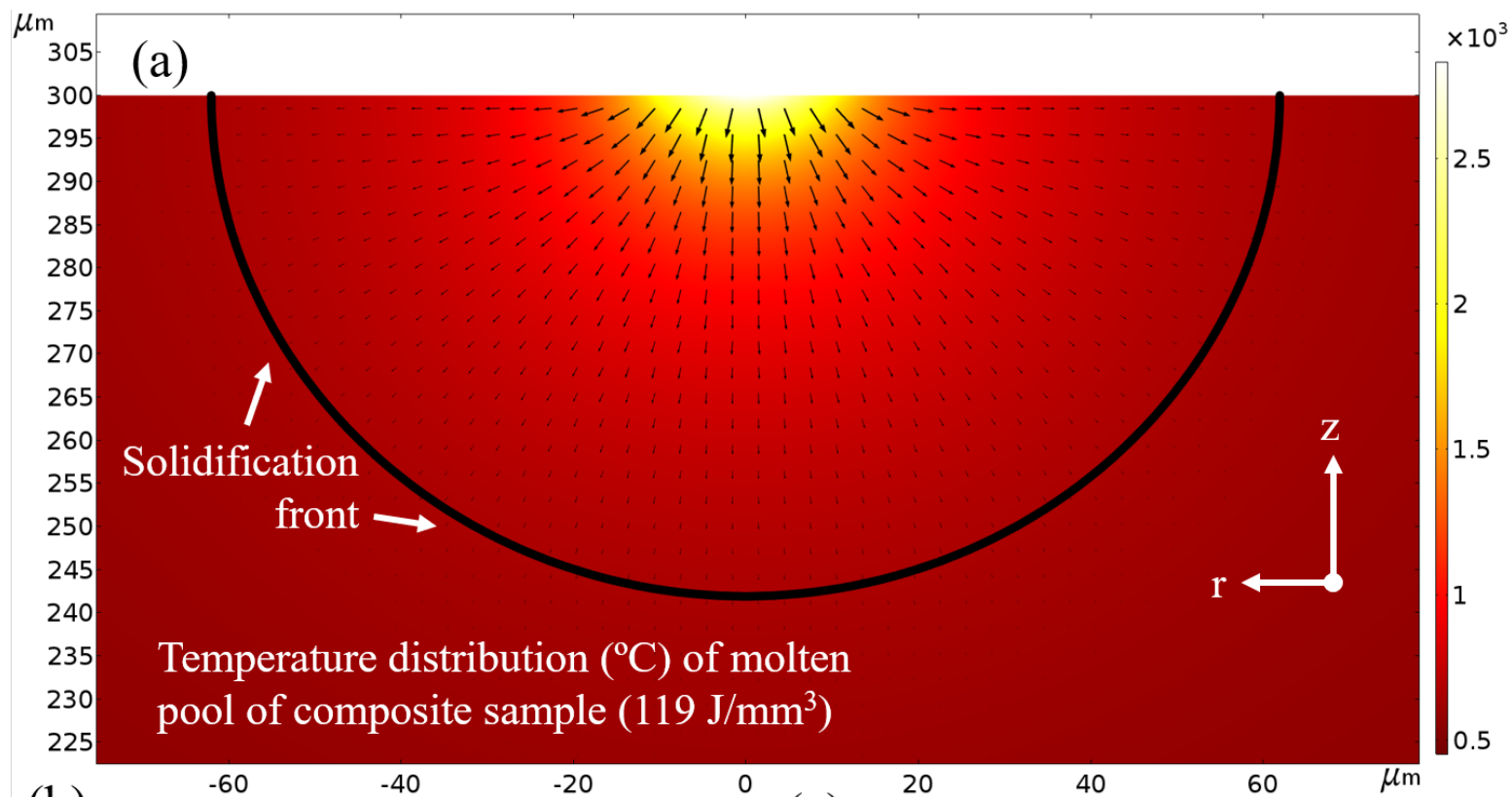

(b)

(c)
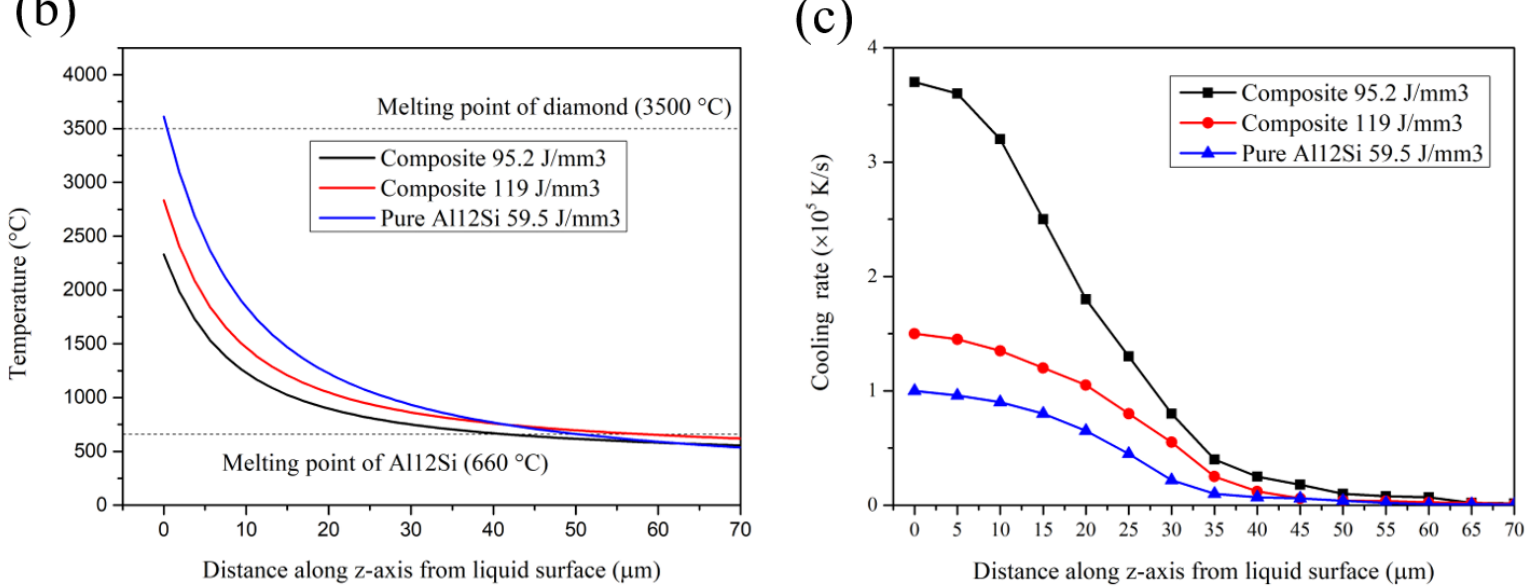

Figure 12 